\title{
О СОДЕРЖАТЕЛЬНЫХ И ПРАГМАТИЧЕСКИХ ОСОБЕННОСТЯХ РАЗЛИЧНЫХ ВИДОВ РЕЧЕВОГО АКТА ЗАПРЕТА
}

Речевой акт запрета обычно классифицируется как один из видов директивных речевых актов. Помимо запрета директивными речевыми действиями считаются приказы, просьбы [3, с.271], поручения, разрешения, приглашения, подстрекательство, подзывание, склонение [Л.М.Васильев, 1971 цитир. по 2, с.127], а также требования, советы, вопросы [Р.Бах и Р.М.Харниш, 1979 цитир. по 2, с.129]; включают сюда часто и согласие, отказ и др. Бросается в глаза, что списки директивных речевых действий состоят из разноуровневых образований и сильно различаются по охвату коммуникативных ситуаций, т.е. «исследователи исходят из разной степени абстракции при выделении той или иной группы речевых актов [6, с.117]. В них включаются как акты широкой сферы применения - вопросы, требования, так и акты достаточно узкой сферы использования (подстрекательство, подзывание, приглашение). Не совсем отвечающими понятию директивы (побуждения) представляются речевые акты согласия, отказа, разрешения.

Таким образом, место речевого акта запрета оказывается не совсем четко определенным. Не установлено, какие директивные акты соответствуют ему по уровню, какие могут считаться включающими, и, соответственно, более объемными, а какие, наоборот, сами включаются в акт запрета.

Так, в классификации А.А.Романова запреты относятся к инструктивам, а приказы и требования к инъюнктивам [4, с.55], что на наш взгляд не совсем оправдано, поскольку приказ можно считать формой требования, а запрет - его разновидностью.

Речевой акт запрета фигурирует и в классификации, представленной В.И.Карасиком [1, с. 119]. Он выделяет статустно-маркированные (сюда, как обычно, в общем списке относятся приказы, требования, просьбы, мольбы, предписания, запреты) и статусно-нейтральные речевые акты (утверждения, повествования, описания). В данном случае не совсем удачным представляется выбор основания для классификации. Различия первых и вторых вышеназванных типов речевых актов скорее в реакции слушающих: если требование, просьбы и т.п. предполагают реакцию в виде действия, то утверждения, повествования, описания такой реакции не предполагают. (Отметим, что именно на этом основании подразделял директивные и утвердительные высказывания Ч.Фриз. [7, с.29-53].

Что же касается статусной маркированности, то наблюдения показывают, что запреты не зависят от статуса собеседников и могут быть совершены говорящими любого статуса по отношению к слушающим любого статуса. Так, в следующем примере речевой акт запрета произносится собеседником более низкого статуса: “Smither,” said Soames, “we're all indebted to you”. - “No, Mr. Soames, don't say that! It's pleasure - he’s such a wonderful man!” (11, с. 181 ).

Однако, общей тенденцией в отношении статусов собеседников в ситуации запрета (более 80\% случаев) является равенство статусов - запреты практикуются скорее в среде достаточно близких друг другу людей, например: "Forgive me if I seemed unresponsive. The truth is, Harris was round here this morning - "George said: "Say no more, I understand” (13, с. 32 ). Напротив, в ситуациях, участниками которых оказываются люди, не являющиеся близкими друг другу, запреты как подвид требований в большинстве случаев не применяются, они видоизменяются в рекомендации, советы, предложения, пожелания и т.п. для обеспечения успешности и бесконфликтности коммуникации. 
Вышеописанная особенность акта запрета как вида требования предполагает важный вывод о том, что он является преимущественно прямым и не может быть косвенным, в отличие от многих других речевых актов. Сама суть этого речевого акта предполагает предоставление адресату возможности ясно понять требование говорящего, при этом какое-либо «смягчение» не является необходимым, поскольку, как уже было отмечено, запреты имеют место обычно среди достаточно близко знакомых людей.

Не претендуя на окончательное определение положения акта запрета в классификациях речевых актов, позволим себе высказать предположение, что видами директивных актов одного уровня можно считать требование и просьбу, которые действительно имеют своей иллокутивный целью добиться чего-либо от слушающего, но отличаются способом достижения иллокутивной цели. Требование может носить как положительный, так и отрицательный характер, и отрицательным требованием, то есть требованием не делать чего-либо, является запрет. При этом и собственно требование («положительное» требование сделать что-либо), и запрет могут носить нейтральный характер, когда статус не является существенным для ситуации общения, и характер приказа при более высоком статусе говорящего и наличии у него соответствующей данной ситуации необходимости отдавать приказы. Таким образом, запрет, по нашему мнению, является одним из подвидов директивного акта требования. Каждый из этих подвидов (мы называем их «собственно требование» и «запрет») может быть реализован либо в нейтральной форме, либо в форме приказа.

Запрет, являясь одним из видов требований, в свою очередь, неоднороден по своему содержанию. Эта семантическая неоднородность проявляется прежде всего в отношении ко времени того действия, которое запрещается. В частности, запрещаться может, во-первых, действие, которое только что имело место или имеет место в момент произнесения запрета, например: "Here, there're too many whom you can bide behind; but with her you'll be forced to speak for yourself”. “Don’t say so.” (8; с. 25). Назовем этот речевой акт «запрет-прекращение». Во-вторых, запрещаться может будущее действие; например: She turned her head slowly, peeking over her shoulder. "Don't look down", he warned . "You'll get dizzy” (15 , с. 87). Назовем этот речевой акт «запрет-превентив».

Если проанализировать запрет-прекращение и запрет-превентив с точки зрения условий успешности речевого акта, разработанных Дж. Серлем [5], то можно прийти к выводу, что условия пропозиционального содержания, существенное условие и условие искренности обоих видов запретов совпадают: произнося и то, и другое высказывание, говорящий выражает свою уверенность в необходимости того, чтобы действие не совершалось: говорящий принимает на себя ответственность за то, что его высказывание принесет пользу и является справедливым; говорящий уверен, что действие не должно совершаться, поскольку либо не соответствует данному положению дел, либо может принести вред ему самому, либо его собеседнику или третьему лицу (или лицам).

Однако, подготовительные условия этих актов различны: в случае запретапрекращения запрещаемое действие только что происходило или происходит, длится в момент произнесения запрета, и это действие по каким-то причинам нежелательно, с точки зрения говорящего: “...If you didn’t want to marry her you could have left her. That would have been better than killing her". - "Shut up about her!” (15, с. 195). В случае запрета -превентива действие еще не совершено, но его совершение возможно, т.к. о такой возможности было сообщено говорящему или говорящий сам делает вывод об этой возможности на основе собственных умозаключений о ситуации. При этом говорящий считает реальным нарушение планов по осуществлению данного действия собеседником: "You have to go away and begin your meal, as if you were not going to have any tea at all. You must not even look round at it." (13; c. 15). 
В силу различия этих подготовительных условий, запрет-прекращение может быть отнесен к реактивным речевым актам, а запрет-превентив совмещает в себе черты инициального и реактивного речевых актов, поскольку, с одной стороны, этот запрет является реакцией на описание планов собеседника или ситуации в целом, но, с другой стороны, говорящий провоцирует собеседника как-либо отреагировать на его запрет.

Интересно, что некоторые запреты совмещают в себе черты обоих видов запрета, например: "Yes, Harry, I know what you are going to say. Something dreadful about marriage. Don't say it. Don't even say things of that kind to me again.” (18, c. 114). B данном случае говорящий превентивно запрещает говорить собеседнику на тему брака, однако собеседник явно уже высказывался ранее по этому поводу нежелательным для говорящего образом, и он хочет пресечь такие высказывания. Подобным образом можно прокомментировать и следующий пример превентативно-прекращающего запрета: “...Can’t you see what I'm going through? My God! Don't tell me that you are bad and corrupt and shameful" (18, с. 176).

Анализ подготовительных условий выявляет существование третьего вида запрета, который по своему содержанию отличается от вышеназванных. Это запрет, обозначающий отказ в разрешении сделать что-либо. Подготовительным условием здесь является просьба дать такое разрешение, обычно выраженная в виде вопросительного предложения, например: "Can I take your hat and coat, sir," she said, "and give then a good dry in the kitchen?" "No," he said without turning (17, с. 5). Этот речевой акт запрета можно условно назвать «запрет-неразрешение». Совершенно очевидно, что этот запрет является реактивным.

Выявление трех содержательных разновидностей акта запрета, обусловленных различием подготовительных условий, требует описания наиболее типичных лингвистических характеристик каждого из них.

Наиболее частой формой (90\% случаев) выражения запрета-прерывания является императивное высказывание с don't. Причем глаголы, употребляемые в этих императивных высказываниях в 95\% примерах оказались глаголами речи. Т.е. обычно автор запрета требует от собеседника прекратить говорить то, что тот только что говорил, прерывает речь, а не какое-либо другое действие. Запреты-прерывания речи оказались настолько характерными и высоко употребительными, что возникает предположение о конвенциональности такой формы запретов при общении людей. Ситуация, когда собеседник не желает слушать другого собеседника, поскольку сообщаемое ему по каким-либо причинам неприемлемо для него, является достаточно типичной при общении хорошо знающих друг друга людей (что отражается в диалогах театральных спектаклей, поэтому, в частности, пьесы О Уайльда изобилуют запретамипрерываниями речи). Приведем еще несколько примеров:

Lord Windermere: Child, you and she belong to different worlds. Into your world evil has never entered.

Lady Windermere: Don't say that, Arthur, there's the same world for all of us, and good and evil. (19, c. 247 ).

Lady Windermere: You squander on this infamous woman!

Lord Windermere: Margaret! Don't talk like that of Mrs Erlynne, you don't know how unjust it is.” $(19$, c. 171).

“Cases!” interposed the client, impatiently. "Don't talk to me of cases. The general precedent is in a much larger volume than any of your law books" (10, с. 255).

Даже по этим нескольким примерам можно судить о характерных лингвистических и прагматических особенностях императивных запретов-прерываний речи, подтверждаемых всей выборкой. Эти особенности таковы: 
1. В запретном высказывании обязательно (в 100\% случаев) имеется анафорическое местоимение (реже повторение слова другой части речи), указывающее на то, что именно в словах собеседника не устраивает автора запрета: Don't say that: Don't talk like this: Don't speak of it: Don't say so: Don't say such terrible things и т.п.

2. Запретительное высказывание - прерывание речи практически никогда не является конечной репликой. Далее обязательно следует аргументация, объясняющая, почему говорящий не желает слушать прерванную им речь собеседника.

3. Запреты-прерывания речи обычно высоко-эмоциональны (что подтверждается использованием восклицательного знака) и используются в эмоционально насыщенных ситуациях.

Помимо наиболее характерных глаголов talk, speak, say, употребляются и глаголы: blame, interfere, ask, tease, bully и другие глаголы речи.

Следует отметить, что императивные высказывания с don’t являются нейтральной и наиболее типичной формой запрета-прерывания речи. Однако существуют и более разговорные и даже грубые формы такого запрета, например: “Stop! faltered Dorian Gray, "stop! You bewilder me. I don't know what to say. There's some answer to you, but I can't find it $(18$, c. 26)

Kay: Now, shut up, Hazel! (15, c.37).

Запрет-прерывание речи, как уже было отмечено, это запрет на только что сказанное, т.е. относится к близкому прошлому. Другие запреты-прерывания относятся к настоящему и обычно являются запретами каких-либо конкретных действий собеседника, производимых им в момент речи говорящего и нежелательных для него по различным причинам. Эти запреты прерывания имеют такую же императивную форму c don’t, как и запреты-прерывания речи, однако круг используемых здесь акциональных глаголов достаточно широк, например:

Lord Windermere: You must know I demand on explanation. Don't hold me, you fool (to Cicil Graham), (19, c. 226).

- Are you alone, then?

- There's a girl living with me. Don't walk so fast; you're out of step!” (14, c. 63)

"Yes, sir," said Trotty, leaving it behind him in a corner. "Don't leave it there, explained the gentleman. "Bring it here, bring it here" (10, c. 95)

I was struck by the difference between her gown and the rest of her dress, and she saw that I noticed it. “Don't look at my bonnet and shawl - " she said, ..." if I mustn't wear white, I don't care what I wear (9, c. 216).

She put her hand upon his arm and looked into his eyes. He thrust her back. "Don't touch me!" he cried (18, c.102).

"I want you to get rid of the dreadful people you associate with. Don't shrug your shoulder like that" (18, с. 174).

Во всех подобных случаях контекстуальное описание показывает, что действие, длящееся во время ситуации речи, нежелательно для одного из участников и вызывает требование прекратить его.

Таким образом, запреты-прерывания распадаются на два подтипа в соответствии с временим прерывания действия (произошедшее в недавнем прошлом или протекающее в настоящем) и в соответствии с содержанием самого действия (в недавнем прошлом обычно имел место нежелательный акт речи, а в настоящем имеет место нежелательное конкретное действие или движение). При этом каждый из названных подтипов запрета имеет характерные и устойчивые лингвистические особенности.

Запрет-превентив, относящийся к будущему действию, так же имеет особенности в способах выражения. Для предотвращения нежелательных для говорящего действий может использоваться сочетание модального глагола, например: 
“No, no, Julia must not be Amelia. It's not at all the part for her. She wouldn’t like it...” (8, c. 138).

"You must not come to this church," said he, "I see you are ill and this church is too cold." (8;c. 149).

Отметим, что форма запрета-превентива с модальным глаголом обычно предполагает запрет не однократного действия в будущем, но действия “вообще”. Этот запрет чаще всего аргументируется, поскольку говорящий серьезно к нему относится. Причем запрет c must может носить характер правила, постоянное соблюдение которого говорящий считает необходимым: "You must not take a cup of tea and a biscuit in place of a regular dinner, because dinner happens to be a trouble” (14, с. 122).

Для предотвращения же конкретных однократных действий в ближайшем будущем используется императив с don't:

Her cheek grew burning hot against my neck, and her arms trembled and tightened around me.

"Don't tell him about the twenty-second," she whispered (9, c.141).

He stepped closer. "The notebook, por favor," he said, extending his left hand. "And don't try anything." (15, c.193)

Winifred's hand gripped his arm. "Don't turn your head," she said in a low voice," but look to your right in the front row of the stand. (11, c.177)

Как можно видеть, такие запреты обычно носят характер предостережения от опасных последствий, которые могут быть эксплицированы или подразумеваться ситуацией, как во втором примере. В некоторых случаях запрет-превентив, выраженный императивом c don’t, приобретает характер инструкции о ближайших действиях; при этом обычно используются несколько параллельных конструкций: Sergeant Holcomb said to Waner, "Waner, you stay here with Mr. Waid. Don't let him leave. Don't let anyone to talk to him. Don't let him touch anything. Do you understand?” (12, c. $56)$.

Наиболее жесткой формой запрета-превентива является конструкция с модальным глаголом shall в отрицательной форме: "You shall not irritate me, Mr. Fairlie - for your niece's sake and for her father's sake, you shall not irritate me.” (9, с. 124) .

Lord Windermere: "Why is my wife's fan here? Answer me! By God. I'll search your rooms and if my wife is here, I'll..."

Lord Darlington: "You shall not search my rooms! You have no right to do so. I forbid you!" $(19$, c. 226).

Заметим, что в последнем примере жесткость такой формы подтверждается перформативным запретным высказыванием.

Таким образом, запрет-превентив так же неоднороден по содержанию. Это может быть либо запрет действий “вообще”, и в этом случае обычно применяется форма c must not, a также имеет место аргументация запрета; либо запрет ближайших будущих однократных или непостоянных конкретных действий, чаще всего в ситуациях предостережения, и в этом случае превалирует императив с don't, a жесткой формой запрета-превентива выступают конструкции с shall not и перформативные конструкции с "I forbid".

Формой запрета-неразрешения обычно выступает местоимение по, поскольку такой запрет является формально ответом на вопрос о том, можно ли сделать что-либо: "Please let me go along with you." - "No!" (16, c.198)

Can Mahtob stay home from school tomorrow? - No! " he supped (16, c. 313)

Let me call your maid - No (8, c. 203).

Как видим, обычно это резкие запреты без аргументации.

Подводя итоги можно констатировать, что неопределенное положение акта запрета в классификациях речевых актов связано с его содержательной неоднородностью. Считая его одним из видов требований, мы рассмотрели его 
содержание с точки зрения подготовительных условий для предъявления требования не делать чего-либо, т.е. запрета. В соответствии с различиями этих условий запреты распадаются на запреты-прерывания, запреты-превентивы и запреты-неразрешения.

Каждый из этих типов запрета характеризуется достаточно устойчивыми лингвистическими способами выражения в английском языке и имеет тенденцию использоваться в определенных ситуациях. Общими прагматическими параметрами этих ситуаций можно считать достаточно высокую степень знакомства участников ситуации и несущественность их статуса для речевого акта запрета, в особенности для запрета-прерывания речи. Несущественным с точки зрения возможности произнести запретное высказывание оказывается и параметр официальности/неофициальности ситуации, хотя этот параметр может повлиять на форму запрета. Важно, что в соответствии с прагматическими условиями ситуаций общения запрет трансформируется в другие речевые акты (советы, предложения, пожелания, угрозы и т.д.), однако, не должен смешиваться с ними, учитывая специфику коммуникативных и содержательных характеристик запрета.

1. Карасик В.И. Язык социального статуса. М.: ИТДГК «Гнозис», 2002. - 331с..

2. Кобозева И.М. Лингвистическая семантика. М.: УРСС, 2000. -350с.

3.Лайонз Дж. Лингвистическая семантика. М.: Языки славянской культуры, 2003. 397c.

4. Романов А.А. Системный анализ регулятивных средств диалогического общения. М.: Институт языкознания АН СССР, 1988. - 187с.

5. Серль Дж.Р. Классификация речевых актов// Новое в зарубежной лингвистике. Вып. 17. М.: Прогресс, 1986. С. 170-194.

6. Формановская Н.И. Речевое общение: коммуникативно-прагматический подход. М.: Русский язык, 2002. -215 c.

7.Fries Ch. The Structure of English. N.Y., 1952. - 205c.

8. Austin J. Mansfield Park. Penguin books, 1994. - 479 c.

9. Collins W. The Woman in White. Wordsworth, 1999. - 346 c.

10. Dickens Ch. Christmas Books. London, 1993. - 200 c.

11.Galsworthy J. To Let. Penguin books, 1967. - 239c.

12.Gardner E.S. The Case of the Perjured Parrot . M. 2002. - 364 c.

13. Jerome K.J. Three Men in a Boat. M.: ВШ, 1976. - 158c.

14. Kipling R. The Light that Failed. Raduga Publishers, 2001. - 334 c.

15. Levin I. A Kiss before Dying. M. 2002. - 371 c.

16. Mahmoody B. Not without My Daughter. Corgi-books, 1987. - 424 c.

17. Wells H. The Invisible Man. M. 2004.- 286 c.

18. Wilde O. The Picture of Dorian Gray. M. 2004.- 304 c.

19. Wilde O. Selected Prose. Penguin books, 1994. - 443c. 